\title{
Barriers to Supplemental Calcium Use Among Women in Suburban Family Practice: A Report from the Cleveland Clinic Ambulatory Research Network (CleAR-eN)
}

\author{
Carl V. Tyler, MD, MS, James J. Werner, PhD, Vanessa Panaite, BA, \\ Sandra M. Snyder, DO, Donald B. Ford, MD, Jessica L. Conway, MD, \\ Christopher W. Young, MD, Brenda L. Powell, MD, Michael J. Smolak, MD, and \\ Stephen J. Zyzanski, PhD
}

Background: The majority of adult women in the United States fail to meet daily calcium intake recommendations. This study was undertaken to (1) identify predictors of calcium supplement use versus non-use, (2) understand barriers to calcium supplementation, and (3) determine the potential impact of physician recommendation on calcium supplement use.

Methods: Surveys were self-administered by 185 women, ages 20 to 64, presenting consecutively for care at 6 suburban community-based family medicine practices within the Cleveland Clinic Ambulatory Research Network (CleAR-eN). We compared demographic characteristics, health beliefs, and health behaviors of those women who reported never using calcium supplements with those who presently took calcium supplements. Women who never took calcium were also queried about reasons for nonuse and whether physician recommendation would influence their adoption of calcium supplementation.

Results: Multivitamin use, self-perceived risk of osteoporosis, and age were independent predictors of calcium supplement use. Leading barriers for never-users were lack of knowledge about the need/ importance of increasing calcium intake, lack of motivation to start supplements, and the belief that their dietary calcium intake alone was sufficient. Ninety-six percent of never-users reported that they would consider taking a calcium supplement if recommended by their physician.

Conclusions: Many patient-identified barriers to calcium supplementation seem amenable to focused and brief office-based interventions that could increase the number of women meeting calcium intake guidelines. (J Am Board Fam Med 2008;21:293-299.)

Observational and intervention studies support the contention that calcium intake is positively associated with bone mass and is an important component of osteoporosis prevention efforts. ${ }^{1-3}$ In the United States, National Health and Nutrition Examination Survey data document that suboptimal

This article was externally peer reviewed.

Submitted 4 April 2007; revised 18 October 2007; accepted 24 October 2007.

From the Department of Family Medicine, Cleveland Clinic (CVT, SMS, DBF, JLC, CWY, BLP, MJS); the Department of Family Medicine (CVT, JJW, VP, SJZ) and the Department of Epidemiology and Biostatistics (SJZ), Case Western Reserve University, Cleveland, Ohio.

Funding: Health Resources and Services Administration (D54HPO5444).

Conflict of interest: none declared.

Corresponding author: Carl V. Tyler, MD, MS, Fairview Hospital/Cleveland Clinic Family Medicine Residency Program, 18200 Lorain Avenue, Cleveland, OH 44111 (E-mail: carl.tyler@fairviewhospital.org). calcium intake (including foods, supplements, and antacids) is widespread. ${ }^{4}$ Among women ages 20 to 49 years only $40 \%$ met calcium intake recommendations, whereas among women aged 50 and older a dismal 27\% achieved them. Healthy People 2010 aims for $75 \%$ of women to meet their goal calcium intakes. $^{5}$

One strategy is to enhance the effectiveness of calcium intake counseling already provided by family physicians. Approximately one half of adult women recall receiving some type of advice about calcium intake from their family physician. ${ }^{6,7}$ However, little is known about the content or impact of such discussions.

Limited information is available regarding the characteristics of women in primary care settings who fail to achieve recommended intakes. A study of Wisconsin women attending primary care clinics found lower calcium intakes among those who were 
premenopausal, younger, smokers, non-white, or who were without a diagnosis of osteopenia or osteoporosis. ${ }^{8}$ However, the sample of women in this study was unusual in that they reported average intakes more than twice the national average.

The purpose of our study was to identify potential strategies for improving calcium intake among adult women in primary care practices through: (1) comparing demographic, health behavior, and health beliefs of women who presently take calcium supplements with those who never have; (2) identifying patient-reported barriers to calcium supplementation; and (3) determining the potential impact of physician recommendation on calcium supplement use.

\section{Methods}

\section{Data Collection}

This study used a nested cross-sectional survey design. Physicians at 6 community family health centers within the CleAR-eN invited women ages 20 to 64 presenting consecutively for routine care to complete a questionnaire regarding their use of calcium supplements. Questionnaires were completed anonymously by patients after their medical visits until an average of 30 were completed at each clinic.

Three versions of the questionnaire were developed reflecting current, never, and former use of calcium supplementation, but only those surveys completed by current users and those who never use supplements are reported here. Although the surveys were specifically developed for this study, items were patterned after those developed and validated in other studies. ${ }^{9,10}$ Questions common to all versions of the survey included demographic information, health behaviors, and health beliefs relevant to calcium intake and osteoporosis prevention. The survey version for those who never use supplements included an open-ended question regarding the main reason for not taking a calcium supplement followed by a closed-ended list of potential barriers derived from the literature and from clinician experience. Never-users also chose a 4-point Likert scale response to the question, "Would you consider taking calcium supplements if your doctor recommended it?"

\section{Data Analysis}

Descriptive statistics were computed for all pertinent variables. Measures of association were com- puted between demographic and health-related items and supplement status. Logistic regression was performed to identify demographic and healthrelated variables independently associated with calcium supplement status. Patients' reasons for not taking a supplement were classified and tallied. Finally, their willingness to take calcium supplements, if so recommended, was tabulated.

Because responses of patients associated with a given physician cannot be regarded as statistically independent, the level of similarity among patients nested within physicians, measured by the intraclass correlation (ICC), was accounted for in the statistical analysis. ${ }^{11}$ Only adjusted test statistics and $P$ values were reported. The study sample size of 30 patients per clinician $(\mathrm{N}=180)$ was estimated a priori based on the following parameters: $\alpha=$ 0.05; power, 0.80; medium effect size, 0.50 ; ICC, 0.02 ; and 6 practice sites. Here we reported findings only for the 148 current users and those who never use supplements. Descriptions of former users of calcium supplementation were found to be complex and the subject of a separate report.

\section{Results}

At each site less than $5 \%$ of women eligible for the survey declined to participate. The totals column in Table 1 summarizes the demographic and healthrelated characteristics of our 185 respondents, of whom 69 were presently taking calcium supplements and 79 had never used calcium supplements. Study site was not associated with any of the variables listed in Table 1.

Treating calcium status as a dichotomous outcome, the ICC for the 6 practice sites was 0.025 , indicating that statistical adjustment for clustering was indeed required. This adjustment reduced the likelihood that the findings reported were merely an artifact of individual differences in physician practice style. Table 1 displays the demographic and history variables that differentiated the 2 calcium supplement groups. When compared with those who never use calcium supplements, current users, on average, were 8 years older $(P=.001)$, were twice as likely to take a daily multivitamin $(P=.001)$, and more frequently scheduled physical exams $(P=.02)$. Current users also reported higher rates of both family history $(P=.02)$ and personal risk for osteoporosis $(P=.006)$ and were better educated $(P=.02)$. 
Table 1. Demographic and Medical History Items by Calcium Supplementation Status Among Women in 6 Ohio Family Medicine Practices

\begin{tabular}{|c|c|c|c|c|}
\hline Item Stem & $\begin{array}{l}\text { Current Users } \\
\quad(\mathrm{n}=69)\end{array}$ & $\begin{array}{l}\text { Non Users } \\
(\mathrm{n}=79)\end{array}$ & $\begin{array}{c}\text { Totals } \\
(\mathrm{n}=185)\end{array}$ & $P^{*}$ \\
\hline Age (mean) & 48 & 40 & 43 & .001 \\
\hline Do you take a daily multivitamin? (\% yes) & 80 & 40 & 55 & .001 \\
\hline Personal risk for osteoporosis (\% yes) & 63 & 34 & 50 & .006 \\
\hline Level of education (\% any college) & 94 & 76 & 84 & .02 \\
\hline Family history of osteoporosis (\% yes) & 41 & 18 & 32 & .02 \\
\hline Schedule regular physical exam (\% yes) & 93 & 75 & 84 & .02 \\
\hline Children under your care (\% yes) & 45 & 60 & 54 & .16 \\
\hline Health status (\% fair) & 6 & 15 & 10 & .17 \\
\hline Elderly adults under your care (\% yes) & 23 & 13 & 15 & .18 \\
\hline Marital status (\% married) & 62 & 75 & 70 & .20 \\
\hline Smoking status (\% yes) & 13 & 13 & 13 & .96 \\
\hline
\end{tabular}

*All $P$ values refer to $\chi^{2}$ tests except for the $t$ test used to compare mean age differences.

Using logistic regression analysis, 3 variables were found to independently discriminate between users and non-users of calcium supplements: selfrated risk for osteoporosis, multivitamin use, and chronological age (Table 2). These 3 variables correctly classified $75 \%$ (50 of 67 patients) of current calcium supplements users and $77 \%$ (58 of 74) of those who never used supplements (Table 3). A more frequent perceived personal risk of osteoporosis, multivitamin use, and older age characterized current users, whereas non-users reported the lowest levels for all 3 variables.

Among those who never used supplements, $86 \%$ (68 of 79) of women answered the open-ended question regarding non-use. The primary reason for non-use in $55 \%$ (37 of 68 ) of respondents suggested a lack of basic knowledge about the importance of calcium, such as "I didn't realize it was necessary," or "my doctor never mentioned it." Nineteen percent believed their diets alone provided sufficient calcium. Only $8 \%$ referenced intrinsic difficulties with taking supplements such as cost, convenience, or taste. Interestingly, 4\% blamed side effects such as constipation or upset stomach for non-use, suggesting a previous trial of supplementation.

Table 4 tabulates the responses of patients who have never used supplements to forced-choice dichotomous close-ended questions about their reasons for not using supplements. These results closely correspond to the reasons given to the open-ended question. The major themes emerging from both the open and closed-ended probes include (1) the lack of a physician's recommendation to increase calcium intake, (2) a lack of information regarding the need for increasing calcium intake and (3) a lack of motivation to increase calcium intake.

Lastly, 56\% (44 of 79) of those who never use supplements reported that they would be "very likely" to take a calcium supplement if their doctor recommended it, and a substantial $96 \%$ said that they would either be "very likely" or "somewhat likely" to take a calcium supplement if their doctor recommended it.

Table 2. Significant Independent Predictors of Current and Non-Users of Calcium Supplements by Logistic Regression*

\begin{tabular}{lccccc}
\hline Variable & $\begin{array}{c}\text { Current Users } \\
(\mathrm{n}=69)\end{array}$ & $\begin{array}{c}\text { Non-Users } \\
(\mathrm{n}=79)\end{array}$ & Wald Statistic & $P$ & Odds Ratio (95\% CI) \\
\hline Age (Mean) & 48 & 40 & 8.77 & .003 & $1.06(1.02-1.09)$ \\
Take a multivitamin (\% yes) & 80 & 40 & 17.20 & .001 & $5.77(2.52-13.21)$ \\
Osteoporosis risk (\% yes) & 63 & 34 & 8.44 & .004 & $3.24(1.47-7.17)$ \\
\hline
\end{tabular}

*All variables in Table 1 were entered into the model. 
Table 3. Classification of Current and Non-Users of Calcium Supplements by Logistic Regression

\begin{tabular}{lccr}
\hline & \multicolumn{3}{c}{ Predicted Status } \\
\cline { 2 - 3 } Actual Status & Never User & Current User & Totals \\
\hline Never User (n [\%]) & $57(77)$ & $17(23)$ & $74(100)$ \\
Current User (n [\%]) & $17(25)$ & $50(75)$ & $67(100)$ \\
Totals & 74 & 67 & 141 \\
\hline
\end{tabular}

\section{Discussion}

This study accomplishes a critical step in achieving one of Healthy People $2010^{5}$ nutritional goals: it identifies a set of common, remediable patientidentified barriers to calcium supplement use by adult women. A frequent patient explanation for lack of supplement use was that their physician had never recommended it. Furthermore, $96 \%$ of nonusers indicated that physician recommendation would motivate them to begin supplementation. These findings provide a framework on which brief office-based counseling strategies to increase calcium intake can be developed.

\section{Characteristics of Supplement Users and Non-users}

A profile of non-users emerged: they are younger, more likely to be married with children, and less likely to take time for physical exams than currentusers. These seem to be busy women who have multiple demands competing for their time, and calcium supplementation is either low on their list of priorities or absent from their awareness. Al-

Table 4. Reasons for Never Using Calcium Supplements*

\begin{tabular}{lc}
\hline Item & $\begin{array}{c}\text { Agree (\%) } \\
(\mathrm{n}=79)\end{array}$ \\
\hline Never got into the habit. & 91 \\
I don't know what amount to take. & 79 \\
It is not a high priority for me. & 77 \\
No particular reason. & 75 \\
I get enough from diet. & 66 \\
Doctor never recommended calcium & 57 \\
$\quad$ supplements. & 56 \\
I don't like to take pills. & 50 \\
Didn't know I was supposed to. & 40 \\
The multivitamin has the calcium I need. & 32 \\
Experts do not seem to agree. & 30 \\
I don't want to spend money on calcium. & 13 \\
I worry calcium causes kidney stones. & \\
\hline
\end{tabular}

*These potential barriers were presented as dichotomous, closed-end questions. though adequate calcium intake in early adulthood is essential for achieving maximum lifetime bone density, ${ }^{12} 77 \%$ of our non-users reported that calcium supplementation is not a high priority. Thus, messages about the importance of increasing calcium intake seemed to be significantly less likely to reach women during the period when they have the greatest opportunity to impact their bone density. One strategy might be to engage mothers in discussions about all of the family's calcium intake needs in the context of their children's preventive health exams.

Prior research has suggested women rate their susceptibility to osteoporosis primarily based on their family history, ${ }^{13}$ and that perceived risk motivates women to engage in osteoporosis-preventing behaviors. ${ }^{14}$ This is congruent with our study, in which calcium users were both more likely to report a family history of osteoporosis and more likely to see themselves at personal risk for osteoporosis. Thus, a more extensive inquiry into clinical indicators of osteoporosis in family members, such as spinal fractures or deformities, wrist fractures, or loss of height (as well as the more common questions about a family history of hip fractures) might motivate some women to enhance their calcium intake.

\section{Barriers to Calcium Supplementation}

In our sample, high educational achievement did not ensure calcium supplement use. Many of these women still required specific information about calcium intake, including dietary contributions, target amounts, and potential risks. Nearly $80 \%$ of those who had never used supplements did not know how much supplemental calcium to take. Although national nutritional survey data would suggest that less than one third of women achieve sufficient calcium intakes through diet alone, ${ }^{15}$ two thirds of our sample believed they did. Adult multivitamins in the United States typically contain just $200 \mathrm{mg}$ of calcium or less, but $40 \%$ of our respon- 
dents believed that their multivitamin contained all the calcium they needed.

It also seems that our respondents over-estimated the risk of kidney stones caused by supplemental calcium. In an 8-year prospective study of 96,245 female nurses, a higher dietary intake of calcium was associated with reduced risk of nephrolithiasis, whereas calcium supplementation bore no association with risk. ${ }^{16}$

In our sample, $32 \%$ of women who had never used supplements endorsed the statement that "experts do not seem to agree" about the need for calcium supplementation. These women may need more careful explanation about the limitations and implications of specific high-profile studies. The calcium plus D trial of the Women's Health Initiative was widely interpreted by the lay press as proof that calcium supplementation was of no benefit in postmenopausal women, exemplary of a "state of confusion" regarding women's health in general. ${ }^{17}$ Physicians may need to explain that study participants, before randomization, were already taking, on average, $1148 \mathrm{mg}$ of calcium. ${ }^{18}$ In comparison, National Health and Nutrition Examination Survey III data reported average intakes for similarly aged women as less than half that amount. ${ }^{4}$

Interestingly, among our respondents, side effects and cost of supplements were rarely reported as barriers to supplement use. Because intestinal absorption of calcium is limited to $500 \mathrm{mg}$ dose aliquots, women with limited dietary calcium intake require multiple doses of supplemental calcium - a particular problem for the $56 \%$ of nonusers who indicated they "don't like to take pills." Lessons learned from tackling issues of medication adherence in hypertension and other chronic diseases may prove applicable to calcium supplementation. ${ }^{19}$

\section{Limitations}

Potential limitations of this study begin with the population from which this survey was conducted: women from suburban practices within a single integrated health care system who were highly educated. The generalizability of our findings to lessereducated populations is unknown. However, women with less education tend to have less awareness of family health history as a risk factor for disease; are less likely to actively collect family health history; ${ }^{20}$ are less likely to believe they are personally susceptible to osteoporosis; ${ }^{14}$ and are less likely to engage in osteoporosis prevention behaviors. ${ }^{21}$ At the same time, Nationwide Food Consumption Survey da$\mathrm{ta}^{22}$ documented that even people earning the highest income levels achieved mean per capita daily calcium intakes of $784 \mathrm{mg}$, barely $100 \mathrm{mg}$ greater that those at the lowest income level.

We did not attempt to tally total calcium intake, inclusive of both dietary and supplemental sources. Still, 79\% of non-users were unsure of their personal calcium supplement requirements, reflecting either an inability to calculate their own dietary calcium intake, a lack of knowledge of their total daily calcium recommendations, or both. Given the fact that few women in the United States achieve adequate intakes through dietary sources alone, ${ }^{12}$ in the final analysis, most women will require at least some supplement use. We also did not corroborate, through chart review or other methods, any of the information self-reported by respondents, including multivitamin use and family history of osteoporosis.

\section{Brief Calcium Intake Counseling}

In the Direct Observation of Primary Care study, nutritional counseling by family physicians occurred in $24 \%$ of all patient visits and averaged less than 1 minute. ${ }^{23}$ Nutritional counseling should also address the adequacy of vitamin D intake. Calcium intake counseling in the physician's office begins with a rapid estimate of average daily dietary and supplemental calcium intake. Several web-based osteoporosis prevention sites include "calcium calculators" that enable patients to tally their total dietary intakes. ${ }^{24,25}$ Alternatively, because most dietary calcium is obtained through dairy products, a simpler method is to inquire about the average number of dairy products consumed per day. Crudely estimated, a cup of milk, a cup of yogurt, and $1 \frac{1}{2}$ ounces of cheese each provide about 300 $\mathrm{mg}$ of calcium. Women under age 50 require the equivalent of 3 dairy product servings ( $900 \mathrm{mg}$ of calcium) per day; women over age 50 require 4 (1200 mg of calcium.)

Women with insufficient dietary calcium intake can decide whether they wish to meet their deficits through additional dietary sources or through supplements. Calcium supplements should be taken in doses of no more than $500 \mathrm{mg}$ of elemental calcium and should also contain 200 IU of supplemental vitamin D. Although calcium carbonate is the most commonly purchased supplement, calcium citrate 


\begin{tabular}{|c|c|}
\hline Patient Belief/Concern & Physician Response \\
\hline $\begin{array}{l}\text { "No one in my family ever broke their } \\
\text { hip. I'm not at risk for osteoporosis." }\end{array}$ & $\begin{array}{l}\text { "Osteoporosis can cause fractures anywhere, not just the hip. Spinal fractures } \\
\text { are much more common than hip fractures and are frequently never } \\
\text { diagnosed." } \\
\text { "The older we get, the more likely we are to develop osteoporosis. All of } \\
\text { us are at risk for osteoporosis and need to do everything we can to } \\
\text { prevent it." }\end{array}$ \\
\hline "I get enough calcium in my diet." & $\begin{array}{l}\text { "Most people do not. Let's briefly review your diet and estimate your typical } \\
\text { daily calcium intake." }\end{array}$ \\
\hline $\begin{array}{l}\text { "I thought that studies showed calcium } \\
\text { supplements don't help prevent } \\
\text { fractures." }\end{array}$ & $\begin{array}{l}\text { "What studies suggested is that women whose calcium intakes are already at } \\
\text { target don't get a lot of added benefit from taking even more calcium." }\end{array}$ \\
\hline "I don't like to take pills." & $\begin{array}{l}\text { "Let's talk about good dietary sources of calcium. There are also chewable } \\
\text { candy calcium supplements." }\end{array}$ \\
\hline $\begin{array}{l}\text { "But I take a multivitamin every day. Isn't } \\
\text { that enough?" }\end{array}$ & $\begin{array}{l}\text { "Multivitamins alone don't meet your daily requirements. Let's add up how } \\
\text { much calcium you get in a typical day's diet and see how much you need } \\
\text { by supplement." } \\
\text { "Would you rather meet your requirements by diet alone?" }\end{array}$ \\
\hline $\begin{array}{l}\text { "I've already had one kidney stone. I was } \\
\text { told not to drink milk or take any } \\
\text { supplements." }\end{array}$ & $\begin{array}{l}\text { "For most people who have had a kidney stone, the more calcium you } \\
\text { obtain through foods, the lower your risk of additional kidney stones. You } \\
\text { are the type of person who would best meet your calcium needs primarily } \\
\text { through diet. There are many non-dairy calcium- rich foods such as } \\
\text { fortified cereals and orange juice." }\end{array}$ \\
\hline
\end{tabular}

is better absorbed by people with decreased stomach acid. Table 5 lists counseling strategies that address common barriers to optimum calcium intake.

This study indicates that all women need the clear message, directly from their family physicians, that most do not achieve recommended calcium intakes and that most will not achieve this through diet alone. Subsequent communication should then be tailored to women's specific information needs, misconceptions, and concerns regarding calcium intake. Many of the patient-identified barriers to calcium supplementation seem readily amenable to focused and brief office-based strategies.

We thank Casey Miklowski, MA, and Kathryn Gaughan, BA, for their assistance with this study and manuscript.

\section{References}

1. Welten DC, Kemper HCG, Post CB, Van Staveren WA. A meta-analysis of the effect of calcium intake on bone mass in young and middle aged females and males. J Nutr 1995;125:2802-13.

2. Murray T. Calcium nutrition and osteoporosis. Can Med Assoc J 1996;155:935-9.

3. US Department of Health and Human Services. Bone health and osteoporosis: a report of the Surgeon General. Rockville (MD): US Department of Health and Human Services; 2004.

4. Alaimo K, McDowell MA, Briefel RR, et al. Dietary intake of vitamins, minerals, and fiber of persons ages 2 months and over in the United States: Third National Health and Nutrition Examination Survey, Phase 1, 1988-91. Advance data from vital and health statistics, no, 258. Hyattsville (MD): National Center for Health Statistics; 1994.

5. Office of Disease Prevention and Health Promotion. Healthy People 2010, Vol. II. Focus Area 19: nutrition and overweight. Available from http://www. healthypeople.gov/Document/HTML/Volume2/19 Nutrition.htm. Accessed 11 October 2007.

6. Schrager S, Plane MB, Mundt MP, Stauffacher EA. Osteoporosis prevention counseling during health maintenance examinations. J Fam Pract 2000;49:1099-103.

7. Gourlay ML, Preisser JS, Linville LF, Sloane PD. Survey of osteoporosis preventive care in community family medicine settings. Fam Med 2006;38:724-30.

8. Schrager S, Girard M, Mundt M. Dietary calcium intake among women attending primary care clinics in Wisconsin. WMJ 2005;104:47-50.

9. Cadarette SM, Beaton DE, Hawker GA. Osteoporosis Health Belief Scale: minor changes were required after telephone administration among women. J Clin Epidemiol 2004;57:154-66.

10. Chang S, Chen C, Chen P, Chung U. Predictors of community women's osteoporosis prevention intention-a pilot study. J Nurs Res 2003;11:231-9.

11. Donner A, Klar N. Design and analysis of cluster randomization trials in health research. New York: Oxford University Press; 2000.

12. Valimaki MJ, Karkkainen M, Lamberg-Allardt C, et al. Exercise, smoking and calcium intake during ad- 
olescence and early adulthood as determinants of peak bone mass. BMJ 1994;309:230-5.

13. Gerend MA, Erchull MJ, Aiken LS, Maner JK. Reasons and risk: factors underlying women's perceptions of susceptibility to osteoporosis. Maturitas 2006;55:227-37.

14. Hseih C, Novielli KD, Diamond JJ, Cheruva D. Health beliefs and attitudes toward the prevention of osteoporosis in older women. Menopause 2001;8: 372-6.

15. Fulgoni VL, Huth PJ, DiRienzo DB, Miller GD. Determination of the optimal number of dairy servings to ensure a low prevalence of inadequate calcium intake in Americans. J Am Coll Nutr 2004;23: 651-9.

16. Curhan GC, Willett WC, Knight EL, Stampfer MJ. Dietary factors and the risk of incident kidney stones in younger women: Nurses' Health Study II. Arch Intern Med 2004;164:885-91.

17. Grady D. Women's health studies leave questions in place of uncertainty. The New York Times. 19 February 2006.

18. Jackson RD, La Croix AZ, Gass M, et al. Calcium plus vitamin $\mathrm{D}$ supplementation and the risk of fractures. N Engl J Med 2006;354:669-83.

19. Osterber L, Blaschke T. Adherence to medication. N Engl J Med 2005;353:487-97.
20. Centers for Disease Control and Prevention. Awareness of family health history as a risk factor for disease-United States, 2004. MMWR Morb Mortal Wkly Rep 2004;53:1044-7.

21. Geller SE, Derman R. Knowledge, beliefs, and risk factors for osteoporosis among African American and Hispanic women. J Natl Med Assoc 2001;93:1321.

22. Fleming KH, Heimbach JT. Consumption of calcium in the US: food sources and intake levels. J Nutr 1994;1426S-30S.

23. Eaton CB, Goodwin MA, Stange KC. Direct observation of nutritional counseling in community family practice. Am J Prev Med 2002;23:172-9.

24. Office on Women's Health, US Department of Health and Human Services. Powerful girls have powerful bones. The National Bone Health Campaign. Available from http://www.cdc.gov/powerfulbones/parents/index.html. Accessed 11 October 2007.

25. University of Alabama at Birmingham Osteoporosis Prevention and Treatment Clinic. Tone your bones: a multidisciplinary approach to preventing and treating osteoporosis; 2003. Available from http://www. toneyourbones.org/show.asp?durki $=47462$. Accessed 11 October 2007. 